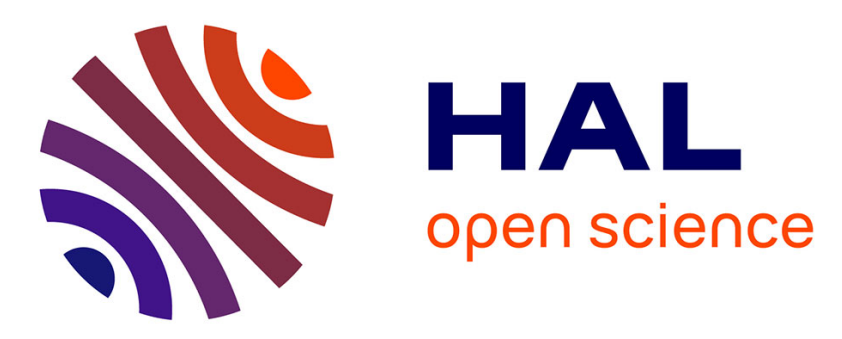

\title{
Identification of Platform Candidates Through Production System Classification Coding
}

Daniel Sorensen, Hoda A. Elmaraghy, Thomas Ditlev Brunoe, Kjeld Nielsen

\section{To cite this version:}

Daniel Sorensen, Hoda A. Elmaraghy, Thomas Ditlev Brunoe, Kjeld Nielsen. Identification of Platform Candidates Through Production System Classification Coding. IFIP International Conference on Advances in Production Management Systems (APMS), Sep 2019, Austin, TX, United States. pp.400407, 10.1007/978-3-030-30000-5_50. hal-02419245

\section{HAL Id: hal-02419245 \\ https://hal.inria.fr/hal-02419245}

Submitted on 19 Dec 2019

HAL is a multi-disciplinary open access archive for the deposit and dissemination of scientific research documents, whether they are published or not. The documents may come from teaching and research institutions in France or abroad, or from public or private research centers.
L'archive ouverte pluridisciplinaire HAL, est destinée au dépôt et à la diffusion de documents scientifiques de niveau recherche, publiés ou non, émanant des établissements d'enseignement et de recherche français ou étrangers, des laboratoires publics ou privés.

\section{(c)(1)}

Distributed under a Creative Commons Attribution| 4.0 International License 


\title{
Identification of Platform Candidates through Production System Classification Coding
}

\author{
Daniel G. H. Sorensen [0000-0001-9395-2411] , Hoda A. ElMaraghy², Thomas Ditlev Bru- \\ noe ${ }^{1[0000-0002-9847-6562]}$ and Kjeld Nielsen ${ }^{10000-0002-3720-167 X]}$ \\ ${ }^{1}$ Mass Customization Group, Aalborg University, Aalborg DK9000, Denmark \\ ${ }^{2}$ Intelligent Manufacturing System Centre, University of Windsor, Windsor, ON, Canada \\ daniel@mp. aau.dk
}

\begin{abstract}
Changeable and reconfigurable manufacturing appears as a natural response to a need for improved variety management. Such manufacturing systems are complicated to develop, and it can be advantageous to base or build these systems on product and production platforms. Development of platforms is, however, not a trivial task. Currently, identification and selection of candidates for inclusion in a platform is typically subjective relying on experts and tacit knowledge. The objectivity of this process can be strengthened by collecting data on existing production systems in a company and comparing these systems to each other. To do so, a coherent, consistent and preferably digital representation of multiple production systems is needed. In this research, a production system classification coding (PSCC) scheme is employed to classify and structure data for a number of existing production systems, spanning multiple departments and product families. Candidates for a production platform covering the included production systems are identified based on ranking certain platform drivers, processes and enablers.
\end{abstract}

Keywords: Manufacturing system, Classification code, Platform.

\section{Introduction}

Manufacturers have long had ambitions of implementing changeable manufacturing. With decreasing product lifecycle and increasing demand for variety, a growing mismatch between product and production lifecycles has appeared [1]. Manufacturing equipment outlives the products it manufactures, and without the ability to adapt to new product variants or generations, outdated and obsolete equipment will simply be taking up valuable resources. Changeable manufacturing appears as a natural response for this need to accommodate change, but systems enabling economic and efficient change are not trivial to create. One path to developing changeable manufacturing systems and managing variety is through use of platforms, a concept involving standardisation of tangible and intangible assets [2]. Within product design and development this concept is well-known, and research on production platforms are gaining foothold, often centred on development alongside products, i.e. co-development and co-platforming [3-5]. Platforms allow companies to develop, manage and use standardised assets for design 
and develop of new systems, whether these are products or production systems. These platforms and assets can take numerous shapes, both tangible (e.g. a physical component or piece of equipment) or intangible (e.g. a specific process ensuring a good result, or knowledge on a certain subject).

Identification and selection of assets to be developed into or included in a platform is one of the first steps in the process. Successful platform development depends on the selection of appropriate assets. A primary source of platform candidates (i.e. assets with a potential for development into or inclusion in platforms) is expert system stakeholders, who base their selection on a detailed understanding of the systems [6]. This understanding is typically tacit knowledge, making it difficult to communicate or grasp the reasoning behind the decisions. Using a more objective method of identifying platform candidates would help system experts and developers explain and back up their decisions, as well as help managers understand these decisions.

In development processes related to product modularisation and platforming, commonality has previously been used as a basis for forming modules and platforms [7, 8]. This commonality, e.g. similar geometries [9] or shared assets [10], can be difficult to identify across large complex systems such as factories and manufacturing systems. To alleviate this, progress has been made towards classifying the processes of manufacturing systems [11], with the intention of using generic and company-specific ontologies to integrate product and production models [12].

This paper presents an effort in identifying potential platform candidates based on data collected from existing manufacturing systems at an industrial partner. The data is a classification of existing manufacturing systems linked to their corresponding cost structure and performance. Focus for this paper is on the classification coding scheme, therefore, the cost and performance data will not be considered in this publication. Platform candidates will be identified as either production processes for which a platform should be developed, or physical equipment which could be developed into a platform. In this paper, physical equipment carrying out or enabling production system operations are generally referred to as "enablers". The use of "enablers" also covers human operators, who can not be considered manufacturing equipment. Based on the above, the following research question has been formulated:

- How can a production system classification coding scheme be used to identify candidates for a production platform?

Firstly, the method is presented with a brief overview of the classification coding scheme. Secondly, the case study is introduced, followed by a description of the results and identified platform candidates. Finally, the paper ends with a discussion of the results, case study and future research.

\section{$2 \quad$ Method}

In order to analyse production systems, a digital representation of them are necessary. For this purpose, a production system classification coding (PSCC) scheme is applied [13]. The scheme is based on ElMaraghy's manufacturing systems complexity, 
coding and classification system [14] and Sorensen's production process classification scheme [11]. It is a hybrid-code considering system design driving requirements, system layout, production processes and enablers. PSCC is essentially used to create a map of a company's production landscape, classifying and documenting manufacturing systems across departments and production locations [13]. A brief overview of the coding scheme and constituent digits is shown on Fig. 1. Digits D1-D9 capture characteristics for the manufacturing system as a whole, specifically the design drivers (or rationale) and physical layout. Digits D10-D25 classify the individual processes performed by the manufacturing system and the enablers that carry them out. Thus, digits D1-D9 are filled out once per manufacturing system, while multiple instances of D10-D25 exist.

\begin{tabular}{|c|c|c|c|c|c|c|c|c|c|c|c|c|c|c|c|c|c|c|c|c|c|c|c|c|}
\hline \multicolumn{9}{|c|}{ System Level } & \multicolumn{16}{|c|}{ Cell/Station Level } \\
\hline \multicolumn{5}{|c|}{ Design Driver } & \multicolumn{4}{|c|}{ Layout } & \multicolumn{6}{|c|}{ Processes } & \multicolumn{10}{|c|}{ Enablers } \\
\hline D1 & D2 & D3 & D4 & D5 & D6 & D7 & D8 & D9 & D10 & D11 & D12 & D13 & D14 & D15 & D16 & D17 & D18 & D19 & 9 D20 & D21 & D22 & D23 & D24 & D25 \\
\hline 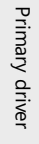 & 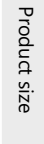 & 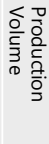 & 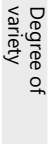 & 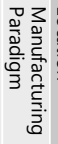 & 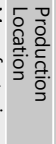 & 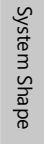 & 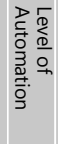 & 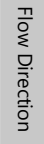 & $\frac{\varrho}{\grave{D}}$ & 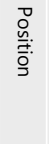 & 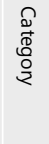 & 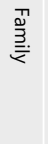 & $\stackrel{\text { Oे }}{\stackrel{\tilde{N}}{\sim}}$ & $\begin{array}{l}\tilde{E} \\
\overline{0} \\
\dot{1} \\
\tilde{\tilde{\nu}} \\
\tilde{n}\end{array}$ & $\begin{array}{l}\text { o. } \\
\text { 足. } \\
\text { ⿳亠丷厂巾亍 }\end{array}$ & 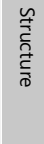 & 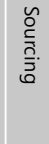 & 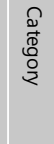 & ఫ্ঠ & 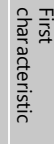 & 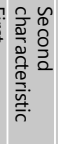 & 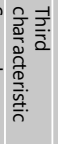 & 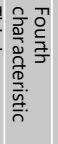 & 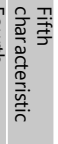 \\
\hline
\end{tabular}

Fig. 1. Overview of the 25 digits in the Production System Classification Coding Scheme (PSCC).

To identify platform candidates based on the PSCC, the populated code for a number of manufacturing systems will be analysed according to certain drivers, outlined in the following section. Potential candidates will be ranked according to each driver, giving each candidate multiple scores. A consolidated score is then used to create the final ranking of candidates.

\subsection{Drivers for Platform Candidate Identification}

A drivers is the driving force, or impetus, which sets something in motion towards a certain destination or state. In the case of identification of platform candidates, drivers are the reasons why a certain asset, whether process or enabler, should be considered a potential platform candidate. The following three drivers are examples of such reasons, which can be determined based solely on the data captured by the PSCC.

1. Frequency: Number of instances of a particular process or enabler across all systems. Frequency does not consider how many times a process or enabler is used e.g. per day. More frequently occurring processes and enablers are ranked higher.

2. Prevalence: Ratio between how many systems a particular process or enabler is used in and the total number of scoped systems. Processes and enablers appearing in more systems are ranked higher.

3. Enabler/process ratio: How many different enablers exist for each process and vice versa. Processes with fewer distinct enablers relative to how often they are carried out are given a higher rank, and similarly for enablers and distinct processes. This driver is also used to determine the number of distinct enablers per type of enabler. 


\section{Case Study}

A case study is used to illustrate the application of the PSCC and determine which processes or enablers are appropriate for inclusion in a production platform,. This case study was carried out in collaboration with a large Danish manufacturer of discrete products. It covered nine distinct production systems at two different company factories in two different countries. The nine production systems span two departments, assembling products or components for subsequent internal use, others assembling complete products for OEM customers. Automation level, product size and production cycle time vary greatly across the systems. The products manufactured by the systems share the same primary function, but with a variety of supporting and additional functions, aimed at different applications and customer segments.

All nine systems have previously been surveyed for various purposes. Using the data collected on this occasion, each system was classified in accordance with the PSCC. The classified systems were then linked to their respective cost and performance data, which were available in an online data hub. Cost and performance data is not, however, considered in this study as the quality of this data has not been sufficiently ensured. A sample of the available data is illustrated in Error! Reference source not found.

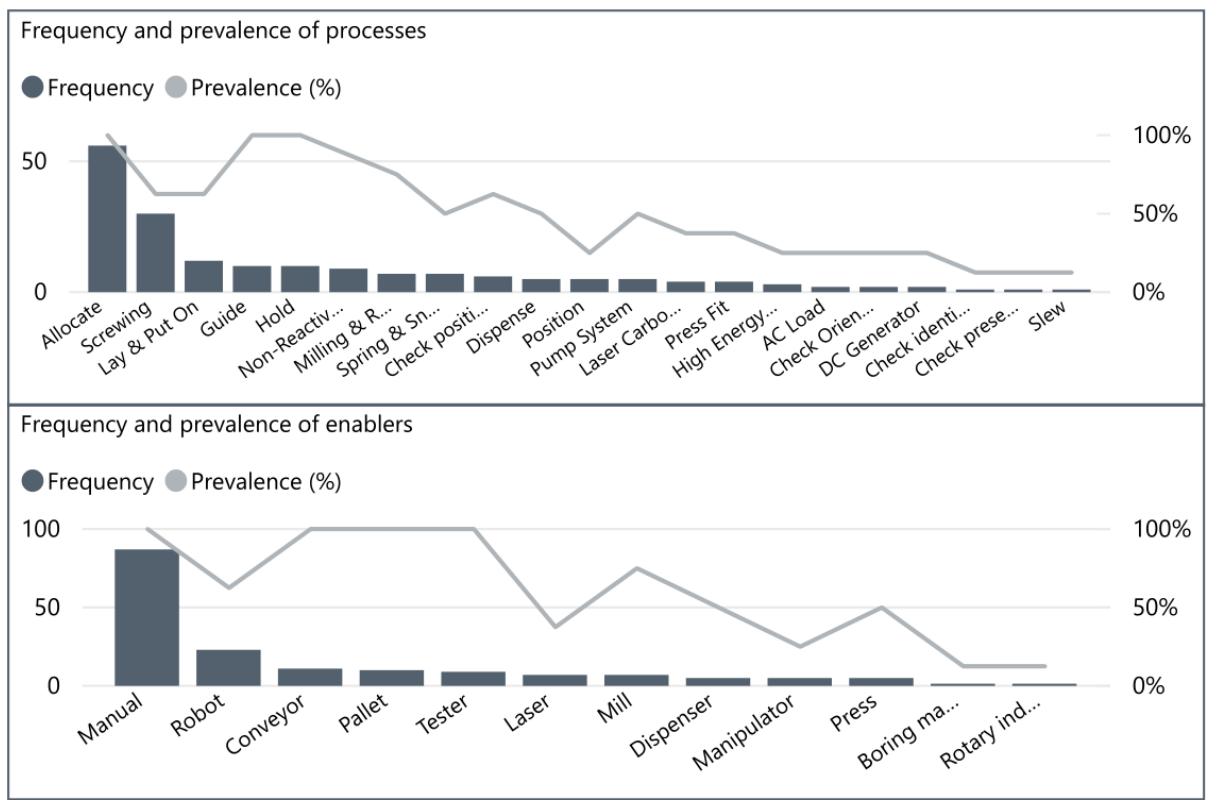

Fig. 2. Graphs of frequency and prevalence for processes (top) and enablers (bottom). 


\section{$4 \quad$ Results}

The ranking of process subclasses and enabler types, digits D15 and D20 in the PSCC respectively, are available in Tables 1 and 2. In total, 21 different process subclasses and 12 different enabler types are considered.

Table 1. Process subclasses ranked according to the three drivers. Sorted by total rank.

\begin{tabular}{|c|c|c|c|c|c|c|c|c|}
\hline Process & $\begin{array}{l}\frac{T}{0} \\
0 \\
0 \\
0 \\
0 \\
0\end{array}$ & 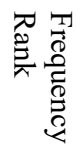 & 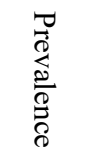 & 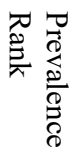 & 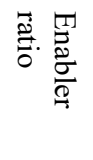 & 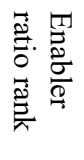 & $\begin{array}{l}\overrightarrow{0} \\
\stackrel{0}{D} \\
n \\
0 \\
0 \\
0\end{array}$ & $\begin{array}{l}\overrightarrow{0} \\
\stackrel{0}{0} \\
\stackrel{0}{0} \\
\text { 莫 }\end{array}$ \\
\hline Allocate & $\overline{56}$ & 1 & 1.000 & 1 & 0.089 & 2 & 4 & 1 \\
\hline Screwing & 30 & 2 & 0.556 & 7 & 0.067 & 1 & 10 & 2 \\
\hline Guide & 10 & 4 & 1.000 & 1 & 0.300 & 7 & 12 & 3 \\
\hline Hold & 10 & 4 & 1.000 & 1 & 0.300 & 7 & 12 & 3 \\
\hline Milling \& routing & 7 & 7 & 0.778 & 4 & 0.286 & 6 & 17 & 5 \\
\hline Non-reactive adhesive bonding & 9 & 6 & 0.778 & 4 & 0.444 & 11 & 21 & 6 \\
\hline Lay \& put on & 12 & 3 & 0.667 & 6 & 0.667 & 16 & 25 & 7 \\
\hline Laser carbonization & 4 & 13 & 0.444 & 10 & 0.250 & 4 & 27 & 8 \\
\hline Position & 5 & 10 & 0.222 & 14 & 0.200 & 3 & 27 & 8 \\
\hline Press fit & 4 & 13 & 0.444 & 10 & 0.25 & 4 & 27 & 8 \\
\hline Spring \& snap fit & 7 & 7 & 0.444 & 10 & 0.429 & 10 & 27 & 8 \\
\hline Check position & 6 & 9 & 0.556 & 7 & 0.500 & 12 & 28 & 12 \\
\hline Dispense & 5 & 10 & 0.556 & & 0.600 & 15 & 32 & 13 \\
\hline Pump system test & 5 & 10 & 0.556 & 7 & 0.800 & 17 & 34 & 14 \\
\hline HEB Welding & 3 & 15 & 0.333 & 13 & 0.333 & 9 & 37 & 15 \\
\hline AC load test & 2 & 16 & 0.222 & 14 & 0.500 & 12 & 42 & 16 \\
\hline Check orientation & 2 & 16 & 0.222 & 14 & 0.500 & 12 & 42 & 16 \\
\hline DC generator test & 2 & 16 & 0.222 & 14 & 1.000 & 18 & 48 & 18 \\
\hline Check identity & 1 & 19 & 0.111 & 18 & 1.000 & 18 & 55 & 19 \\
\hline Check presence & 1 & 19 & 0.111 & 18 & 1.000 & 18 & 55 & 19 \\
\hline Slew & 1 & 19 & 0.111 & 18 & 1.000 & 18 & 55 & 19 \\
\hline
\end{tabular}

Table 2. Enabler types ranked by the three drivers, sorted by total score.

\begin{tabular}{|c|c|c|c|c|c|c|c|c|c|c|}
\hline Enabler & 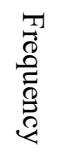 & 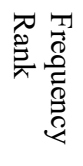 & $\begin{array}{l}\overrightarrow{0} \\
\stackrel{0}{+} \\
\stackrel{0}{0} \\
\stackrel{0}{0}\end{array}$ & 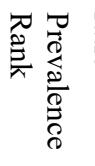 & 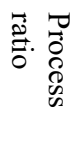 & 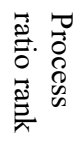 & 苞 & 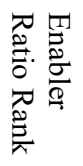 & $\begin{array}{l}\overrightarrow{0} \\
\stackrel{0}{D} \\
\tilde{D} \\
0 \\
0 \\
0\end{array}$ & 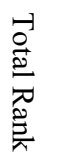 \\
\hline Manual & 89 & 1 & 1.000 & 1 & 0.067 & & 10.067 & 1 & 4 & 1 \\
\hline Conveyor & 11 & 3 & 1.000 & 1 & 0.182 & 5 & 50.273 & 4 & 13 & 7 \\
\hline Pallet & 10 & 4 & +1.000 & 1 & 0.100 & & 20.300 & 7 & 14 & 3 \\
\hline Robot & 23 & 2 & 0.667 & 6 & 0.174 & & 40.261 & 3 & 15 & 4 \\
\hline Mill & 7 & 6 & 50.778 & & 0.143 & & 30.286 & 5 & 19 & 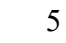 \\
\hline Tester & 9 & 5 & 51.000 & 1 & 0.333 & c & 90.333 & 8 & 23 & 6 \\
\hline Manipulator & 5 & 8 & 0.222 & 10 & 0.200 & & 60.200 & 2 & 26 & 7 \\
\hline Laser & 7 & 6 & 50.444 & 8 & 0.286 & & 80.286 & 5 & 27 & 8 \\
\hline
\end{tabular}




\begin{tabular}{lrrrrrrrrrr} 
Dispenser & 5 & 8 & 0.444 & 8 & 0.200 & 6 & 0.600 & 10 & 32 & 9 \\
Press & 5 & 8 & 0.556 & 6 & 0.400 & 10 & 0.400 & 9 & 33 & 10 \\
Boring machine & 1 & 11 & 0.111 & 11 & 1.000 & 11 & 1.000 & 11 & 44 & 11 \\
Rotary index table & 1 & 11 & 0.111 & 11 & 1.000 & 11 & 1.000 & 11 & 44 & 11 \\
\hline
\end{tabular}

Allocate, with a final rank of 1 , is an obvious candidate. It is defined as the process of creating a partial quantity of parts or components of a certain size, and the movement of said quantity to a target location [11]. Thus, allocate is a material handling process, where new parts or components are assigned a manufacturing system or process. Considering its low enabler variety combined with the high frequency and prevalence, it is likely that a platform already exists for allocate, or that there is simply an agreed upon way to carry out this process. If a platform does exist, it needs to be documented, and if it is merely an agreed upon way to carry out the process, it should be developed into an actual platform module and documented as such.

The highest ranked process in the manufacturing category is screwing. While it only ranks 7 in prevalence, it has a high frequency and a low variety, with only two different enabler types. With only one boring machine present across the nine systems, the remaining 29 instances of the processes are carried out manually, meaning this process may already be standardized, and fit for formal development into a platform.

For enablers, the manual enabler, i.e. an operator, clearly comes out on top in all four measures, with the conveyors and product/component pallets coming in second and third. All three have a high prevalence (1.000), low process variety $(0.067,0.182$ and 0.100 ) and 3 or more distinct enablers, making them good candidates for standardization of enablers. The tester, based on its high prevalence (1.000) and relatively high process and enabler variety ( 0.333 for both) should also be considered for inclusion in a production platform, with the goal of lowering the variety and standardizing testing equipment and process. Finally, the robot enabler is a potential candidate, as it comes in second in frequency and carries out four different processes with six distinct enablers.

\section{Discussion and Conclusions}

A production system classification coding scheme has been used in a case study to classify nine surveyed manufacturing systems. The resulting data is a digital representation of each manufacturing system, its characteristics, structure and functions. Based on three generic drivers for platform identification, the classified manufacturing systems are analysed to identify platform candidates. Candidate processes or enablers are rated and ranked according to these drivers with the highest ranked candidates being recommended for further development into platforms. The PSCC classification coding scheme and subsequent comparison of processes and enablers act as a decision support tool for manufacturers looking to develop production platforms based on their existing production systems, i.e. brownfield platform development.

Additional platform candidate drivers should be considered and added to the rating and ranking process, depending on the requirements of the specific manufacturer. For example, the ratio of instances of a given process subclass defined as a core process 
(D10 in the coding scheme, Fig. 1) i.e. used for all product variants on the system. Adding to the list of other factors useful in selecting individual instances of enablers, certain qualitative drivers can be considered. Examples of such are whether individual enablers have: (1) been a bottleneck in their respective system, (2) had a long calibration period, (3) frequently broken down or required extra maintenance or (4) been deemed especially important by system experts.

Implementation of a classification coding scheme such as the one employed in this study is not a trivial task. An appropriate level of detail must be found, if implementation is to be successful, and it is advisable to take a gradual approach, selecting one segment of the production at a time in order to ensure the quality of the gathered data and resulting code.

To improve and strengthen the recommendations made through the identification process, the classified systems should be linked to their related performance and cost data. This would allow companies to correlate system characteristics, performance and cost, thus determining the system characteristics usually resulting in high performance and low cost. As digitalisation and big data are areas of interest for increasing number of manufacturers, this data is becoming more readily available for analysis.

Besides the drivers in Section 2.1, other factors captured in the PSCC can affect the identification and ranking of potential platform candidates. These factors can modify the scores and rankings of individual instances of processes and enablers to improve the confidence in selection of candidates for further development. Their effect on the scores are decided based on the company's requirements. The purpose of this is to determine the individual instances of already identified processes and enablers which should be prioritized for inclusion in the platform. Selecting the instances, upon which the standard for future systems should be based, is an important step in further platform development. This step will be detailed in future research. Three such factors captured by the PSCC are: (1) enabler structure, (2) sourcing and (3) product variety. Enablers with a modular structure are rated higher than enablers with a fixed structure, and those with a changeable structure are rated even higher. Enablers designed and developed inhouse are given a higher rating as it is often a long and costly process, benefiting significantly from standardisation. Finally, processes and enablers in systems handling a higher degree of variety are given a higher rating.

While not captured in the PSCC, the year in which a system was constructed plays a role in selection of candidates. Enablers in newer systems will take priority over enablers in older systems when it comes to inclusion in a production platform.

As previously stated, identification and selection of platform candidates is typically a matter of tacit knowledge held by system experts. When deciding on which platforms to develop, such knowledge can be difficult to back up and communicate. Using a method for platform candidate identification, like the one presented in this paper, would ease the process of making such decisions and backing them up, while improving transparency and standardisation by classifying manufacturing systems throughout the company. It can also lead to the identification of less obvious platform candidates, or platforms that already exist, but have yet to be documented. By identifying platform candidates and developing them further, the development of new systems can be eased through reuse and modification of existing solutions. 


\section{Acknowledgements}

The research presented in this study was conducted at the Mass Customization research group at Aalborg University in Denmark, in collaboration with the Intelligent Manufacturing Systems (IMS) Centre at University of Windsor in Canada.

\section{References}

1. ElMaraghy, H. A., Schuh, G., ElMaraghy, W., Piller, F., Schönsleben, P., Tseng, M., Bernard, A.: Product variety management. CIRP Annals - Manufacturing Technology 62(2), 629-652 (2013).

2. Simpson, T. W.: Product platform design and customization: Status and promise. AI EDAM 18(1), 3-20 (2004).

3. Michaelis, M. T., Johannesson, H.: From dedicated to platform-based co-development of products and manufacturing systems. In: ElMaraghy H.A. (ed.) Enabling manufacturing competitiveness and economic sustainability, pp. 196-202. Springer, Berlin, Heidelberg (2012).

4. ElMaraghy, H. A., Abbas, M.: Products-manufacturing systems co-platforming. CIRP Annals - Manufacturing Technology 64, 407-410 (2015).

5. Abbas, M., ElMaraghy, H. A.: Synthesis and optimization of manufacturing systems configuration using co-platforming. CIRP Journal of Manufacturing Science and Technology 20, 5165 (2018).

6. Sorensen, D. G. H., Brunoe, T. D., Nielsen, K.: Challenges in production and manufacturing systems platform development for changeable manufacturing. Advances in Production Management Systems. Production Management for Data-Driven, Intelligent, Collaborative, and Sustainable Manufacturing, 312-319 (2018)

7. Thevenot, H. J., Simpson, T. W.: Commonality indices for assessing product families. In: Simpson T.W., Siddique Z., Jiao J.R. (eds.) Product platform and product family design: Methods and applications, pp. 107-129. Springer US, New York, NY (2006).

8. Fixson, S. K.: Modularity and commonality research: Past developments and future opportunities. Concurrent Engineering 15(2), 85-111 (2007).

9. Cardone, A., Gupta, S. K., Karnik, M.: A survey of shape similarity assessment algorithms for product design and manufacturing applications. Journal of Computing and Information Science in Engineering 3(2), 109-118 (2003).

10. Kashkoush, M., ElMaraghy, H. A.: Product family formation by matching bill-of-materials trees. CIRP Journal of Manufacturing Science and Technology 12, 1-13 (2016).

11. Sorensen, D. G. H., Brunoe, T. D., Nielsen, K.: A classification scheme for production system processes. Procedia CIRP 72, 609-614 (2018).

12. Brunoe, T. D., Sorensen, D. G. H., Andersen, A., Nielsen, K.: Framework for integrating production system models and product family models. Procedia CIRP 72, 592-597 (2018).

13. Sorensen, D. G. H., ElMaraghy, H. A., Brunoe, T. D., Nielsen, K.: Classification coding of production systems for identification of platform candidates. (2018). In second review.

14. ElMaraghy, H. A.: A complexity code for manufacturing systems. ASME Int. Conf. on Manufacturing Science and Engineering, Symposium on Advances in Process \& System Planning, 625-634 (2006). 